D.O.I.: $10.3895 / \mathrm{S} 1808-04482009000100006$

\title{
MUDANÇA TECNOLÓGICA E INSTITUCIONAL: DISCUSSÃO DO PROCESSO DE CO-EVOLUÇÃO NA INDÚSTRIA AÇUCAREIRA DO SÉCULO XIX NO BRASIL
}

\section{TECHNOLOGICAL AND INSTUTIONAL CHANGE: DISCUSSION OF CO- EVOLUTIONARY PROCESS IN BRAZILIAN SUGAR CANE INDUSTRY OF XIX CENTURY}

\author{
Fabrício Brollo Dunham ${ }^{1}$; José Vitor Bomtempo ${ }^{2}$ \\ ${ }^{1}$ Financiadora de Estudos e Projetos - FINEP - Rio de Janeiro - Brasil \\ fbrollo@finep.gov.br \\ ${ }^{2}$ Universidade Federal do Rio de Janeiro - UFRJ - Rio de Janeiro - Brasil \\ vitor@eq.ufrj.br
}

\begin{abstract}
Resumo
O objetivo do artigo é discutir a mudança tecnológica em co-evolução com a mudança institucional, buscando avançar na conceituação da literatura de sistemas de inovação. A pesquisa utiliza a estruturação dos motores de transformação como ferramenta de análise. A metodologia define o Sistema de Produção e Inovação em Açúcar-SPIA, do qual o processo de modernização industrial da indústria açucareira serve como objeto de análise. O trabalho conclui que a mudança institucional foi condição necessária, mas insuficiente, à mudança tecnológica. A intervenção governamental criou uma nova categoria de agentes - os fornecedores de cana - que passaram a interagir com os engenhos centrais. Entretanto, o valor gerado no processo de modernização industrial não foi repartido entre os engenhos centrais e os fornecedores de cana. O valor foi retido pelos engenhos centrais. Como resultado os aspectos institucionais e tecnológicos não coevoluiram no SPIA. Houve mudança institucional sem a esperada modernização tecnológica da indústria.
\end{abstract}

Palavras-chave: sistema de inovação, motores de transformação, mudança institucional, mudança tecnológica, co-evolução.

\section{Introdução}

O estudo sistêmico da inovação avançou consistentemente ao longo das duas últimas duas décadas. O conceito de sistema de inovação evoluiu de abordagens descritivas de setores industriais para métodos que possibilitam descrever sua dinâmica de transformação. Entretanto, Edquist (2005) observa que a abordagem por meio de sistemas de inovação ainda é conceitualmente difusa. A relativa ausência de estudos empíricos bem fundamentados faz com que os sistemas de inovação 
sejam rotulados como "abordagens" ou "ferramentas conceituais", ao invés de uma teoria. Uma das razões é o direcionamento dos estudos para os aspectos tecnológicos dos processos de inovação, deixando em segundo plano o processo de inovação organizacional.

Castellaci et al. (2005) corrobora com essa lacuna na literatura sobre sistemas de inovação. Para eles os estudos de inovação deveriam se basear no fato de que a mudança e a inércia institucional são aspectos que co-existem na interação dos agentes econômicos. Como conseqüência, a mudança tecnológica sofrida/provocada pelos agentes econômicos não pode ser adequadamente compreendida sem o estudo das relações institucionais e de sua evolução ao longo do tempo. A co-evolução da mudança tecnológica e institucional é freqüentemente citada nos estudos evolucionários da inovação, mas não é apropriadamente analisada.

O objetivo do artigo é avançar na discussão do processo de co-evolução da mudança tecnológica e institucional em sistemas de inovação, utilizando um período selecionado da indústria do açúcar no Brasil. Mudança institucional deve ser compreendida como alterações nas formas, padrões, regras e demais estruturas sociais que alteram o relacionamento entre um ou mais agentes dos sistemas de inovação.

A modernização da indústria brasileira do açúcar no final do século XIX foi o episódio escolhido para lastrear o estudo empírico. O decreto imperial 2.687/1875 é um marco no processo de modernização da atividade açucareira (BRASIL, 1875). O objetivo do governo era melhorar a competitividade do açúcar no mercado externo, um dos principais itens da pauta de exportação do País na época (FURTADO, 1959).

A modernização da indústria do açúcar foi fundamentada na política de garantia de juros, nos empréstimos públicos e na isenção de tarifárias na importação de equipamentos. A política governamental estabeleceu ainda a separação da produção agrícola e industrial, determinando que essas duas atividades não poderiam ser realizadas pelos mesmos agentes econômicos. Criou-se assim uma nova categoria de agentes dentro do sistema de inovação: os fornecedores de cana. A mudança institucional ocorrida em função do decreto 2.687/1875 trouxe implicações que perduraram até os dias de hoje. Entretanto, a mudança institucional não foi suficiente para suportar a esperada modernização tecnológica.

Nesse contexto, o trabalho analisa por que a mudança institucional não co-evoluiu com a mudança tecnológica. E mais, que fatores limitaram a capacidade da mudança institucional suportar o processo de modernização da indústria açucareira. A construção do motor de transformação foi o ferramental metodológico escolhido para explicitar as falhas do processo de modernização e melhorar a capacidade de analisar a mudança institucional.

Os engenhos centrais de açúcar e os fornecedores de cana não repartiram o valor gerado, considerando o novo regime institucional. Os industriais do açúcar e os fornecedores de cana não 
conseguiram estabelecer uma relação sustentável entre as fases agrícola e industrial de produção, capaz de gerar e repartir o valor da atividade açucareira. A apropriação de valor de forma desigual entre os agentes do SPIA impediu que a modernização industrial.

\section{Referencial teórico}

Num escopo amplo, de origem filosófica, Bunge (1979) define que sistema é todo objeto complexo formado por componentes que estejam relacionados a, pelo menos, um outro componente. Lundvall (1992) mantém essa conceituação básica e observa que as estruturas de produção e a definição institucional são duas dimensões importantes para definir os sistemas de Inovação - SI. A abordagem de Lundvall (1992) reconhece que a organização dos SI é influenciada por fatores econômicos, políticos e culturais que ajudam a determinar a escala, direção e sucesso de todas as atividades de inovação. Edquist (1997) identifica que os SI têm uma função, isto é, desempenham um papel para que algum objetivo seja alcançado.

A abordagem sistêmica da inovação ganha impulso com o conceito de sistemas nacionais de inovação, sobre o qual Freeman (1987), Lundvall (1988, 1992) e Nelson (1993) são os autores mais representativos. A base do conceito ainda é a análise da oferta/demanda de Leontief (1941), mas passa a incorporar outros agentes, especialmente os de ciência e tecnologia. A análise é feita em nível nacional, agregando as atividades de pesquisa e desenvolvimento - P\&D e o papel desempenhado pelas universidades, institutos de pesquisa, agências governamentais e formuladores de políticas públicas. Apesar da abrangência, o conceito de sistema nacional de inovação não considera uma análise dinâmica no tempo.

O conceito de sistemas nacionais de inovação inspirou outras derivações. Carlsson (2006) chama atenção para o fato dos SI estarem se tornando globais. O autor identifica que as empresas estariam alocando recursos de P\&D além de seus limites nacionais, buscando absorver conhecimentos tácitos. Furman et al. (2002), apresentam o conceito de capacidade nacional de inovação, capaz de comparar o desempenho das economias baseadas na inovação entre diferentes países. Balzat e Hanusch (2004) consideram que o modelo da capacidade nacional de inovação traz contribuições significativas pois relaciona elementos da teoria de crescimento econômico com uma abordagem moderna e sistêmica da inovação. Cooke at al. (1997) estudam os sistemas regionais de inovação na linha de reduzir o nível de agregação das análises. Os autores trabalham a perspectiva regional tentando explicitar o impacto da localização de indústrias de alta tecnologia, parques tecnológicos, redes de inovação e políticas públicas de incentivo à inovação.

Dentre as abordagens que não privilegiam a abrangência geográfica, se destaca Malerba (2002, 2004) que introduz o conceito de sistema setorial de inovação na literatura. Um sistema 
setorial de produção e inovação é composto por um conjunto de agentes realizando interações de mercado e de não-mercado1 para a criação, produção e venda de produtos setoriais. Para Malerba (2004) a análise do processo de inovação não é condição suficiente para se compreender os SI. A realização e o acúmulo de experiências na produção de bens/serviços é um dos fatores incorporados na conceituação que o autor faz para os SI.

Os conceitos anteriormente apresentados incluem a interação entre diferentes organizações para a geração, uso e difusão de tecnologias. Com exceção do trabalho de Malerba (2004), os conceitos têm em comum o fato de serem estáticos. Sua aplicação não permite extrair mecanismos que expliquem o processo de co-evolução tecnológica e institucional. A revisão bibliográfica identifica quatro linhas de trabalho com características dinâmicas. São elas: os sistemas setoriais de produção e inovação de Malerba (2004), os modelos de Malerba e Orsenigo (1997) e o sistema sócio-técnico de Geels (2004, 2005).

Ao apresentar os sistemas setoriais de produção e inovação, Malerba (2004) estuda o processo de transformação dinâmica dos sistemas, enfatizando o fato de que as fronteiras setoriais não são estáticas. Dois processos provocam a evolução das fronteiras dos sistemas: a criação de variedades e a seleção. A criação de novos agentes é particularmente importante na dinâmica da fronteira dos sistemas setoriais. A seleção de variedades desempenha o papel de reduzir a heterogeneidade. A seleção define o crescimento e o declínio dos grupos de atores, além de reduzir a faixa de atuação na qual as organizações trabalham.

Malerba e Orsenigo (1997) apresentam outros dois modelos de como os sistemas setoriais podem ser transformados: através de uma drástica ruptura (Schumpeter Mark I) ou pela contínua acumulação de conhecimentos (Schumpeter Mark II). No primeiro modelo, novas competências tecnológicas são requeridas. A introdução da inovação no mercado provoca turbulência na indústria e altera o posicionamento competitivo das empresas. No segundo modelo, há um processo de evolução tecnológica, onde a capacidade de acumular conhecimentos permite transformá-los em ganhos de produtividade.

Para Geels (2004), a transição para um novo sistema só ocorre quando dois fatores estão combinados: a existência de uma janela de oportunidade e a existência de uma inovação radical, protegida por nichos. As janelas de oportunidade surgem quando há tensão entre os elementos do sistema. Se uma tensão desestabilizar o sistema sócio-técnico existente, uma inovação radical pode ser introduzida no mercado. Num primeiro momento há uma competição com o sistema anterior e, posteriormente, sua substituição.

1 Interações de mercado são aquelas pautadas pela compra/venda de produtos e serviços. As interações de não-mercado se referem, por exemplo, às atividades de fiscalização do Estado, financiamento de atividades produtivas, superação de barreiras técnicas e sanitárias, entre outras 
Avançando no conceito, Geels (2005) refina o modelo de transformação dos sistemas sóciotécnico e propõe a rota de substituição tecnológica e a rota de transformação ampla. Na primeira o regime é inicialmente estável e caracterizado por desenvolvimentos incrementais. Emergindo de nichos tecnológicos as inovações radicais podem criar força suficiente para contestar o regime sócio-técnico existente. Após um período de ajustes, a dinâmica deste processo resulta num novo regime sócio-técnico. A rota de transformação ampla surge com a instabilidade dos regimes existentes. A falta de solidez no regime sócio-técnico estimula que os atores experimentem outras opções técnicas. Há um grande período de experimentação, que passa por picos de opções e pela posterior redução do número de alternativas. Em um dado momento, uma opção pode se tornar universal e ser aceita por todos.

As abordagens dinâmicas dos SI apresentam duas vertentes. A primeira, analisa as transformações dos sistemas existentes - na avaliação das fronteiras dos sistemas no conceito de Malerba (2004) e no padrão Shumpeter Mark I de Malerba e Orsenigo (1997). A segunda, no surgimento de um novo sistema - nos conceitos de Geels $(2004,2005)$ e no padrão Shumpeter Mark II de Malerba e Orsenigo (1997). As duas vertentes apresentam modelos de como os SI se transformam, especialmente quanto aos aspectos tecnológicos. Pouco é discutido quanto à associação da mudança tecnológica com a mudança institucional.

Até este ponto, a revisão da literatura apresentou a conceituação dos SI, abordando sua dinâmica. O conteúdo revisto forma uma base de trabalho, mas é preciso avançar buscando compreender como os SI se estruturam ao longo do tempo. Conhecendo o processo de estruturação é possível explicitar os elementos associados à mudança institucional e tecnológica com maior clareza.

Jacobsson e Johnson (2000) trazem uma primeira tentativa de interpretar como as funções dos sistemas de inovação - FSI influenciam a estruturação dos SI ao longo do tempo. Os autores argumentam que existe um grande número de forças que concorrem para a formação (ou para impedir a formação) dos novos SI. Estas forças podem atuar de forma individual ou em conjunto, reforçando umas às outras. Com esta observação os autores tentam trabalhar o processo de mudança dos SI através do mapeamento de três funções individuais. Apesar de pautar o problema de uma forma ampla, Jacobsson e Johnson (2000) concluem com um encadeamento linear de funções que devem ser desempenhadas para a estruturação de novos SI. As três funções que precisam ser desempenhadas para a transformação de SI seriam: a criação de variedades na base de conhecimento, o processo de mudança institucional e a formação de agentes pioneiros na geração, difusão e uso das inovações.

Hekkert et al. (2007) trazem um avanço significativo em relação à abordagem de Jacobsson e Johnson (2000), definindo sete funções que os SI devem desempenhar. A idéia básica é a mesma, 
ou seja, a análise da mudança tecnológica deve ser centrada no mapeamento e encadeamento de FSI determinantes para a transformação dos SI. As sete FSI apresentadas por Hekkert et al. (2007) são:

- FSI 1) Atividades empreendedoras - Não existe SI sem empreendedores. O papel dos empreendedores é transformar o potencial de novos conhecimentos, redes de relacionamento e mercados em ações concretas para gerar e tirar vantagem de novas oportunidades de negócio. Os empreendedores podem ser novos entrantes com visão de oportunidade em novos negócios, ou empresas existentes que diversificam sua estratégia de negócio para tirar vantagem de novos desenvolvimentos. A presença de atividades empreendedoras é o primeiro indicador do desempenho de um SI.

- FSI 2) Geração de conhecimentos - A pesquisa, o desenvolvimento tecnológico e a criação de conhecimento são pré-requisitos para os sistemas de inovação. Três indicadores podem ser utilizados para mapear a função ao longo do tempo: projetos de P\&D, patentes e investimentos em P\&D.

- FSI 3) Difusão de conhecimento através de redes - A função essencial das redes de relacionamento é trocar informações. Isso é importante do ponto de vista estrito do P\&D, mas especialmente num contexto heterogêneo onde as atividades de P\&D contemplam o governo, competidores e outros agentes de mercado.

- FSI 4) Direcionamento da pesquisa e do desenvolvimento tecnológico - Como os recursos são quase sempre limitados, quando existem várias opções tecnológicas, é importante especificar um foco para realizar investimentos. Enquanto o desenvolvimento do conhecimento pode ser comparado à criação de variedade tecnológica, o direcionamento da pesquisa é o processo de seleção. O direcionamento da pesquisa não é exclusivamente uma questão de influencia governamental ou de mercado. É normalmente um processo interativo e cumulativo de troca de idéias entre produtores de tecnologia, usuários de tecnologia e diversos outros atores, no qual a própria tecnologia não é uma constante mas uma variável.

- FSI 5) Formação de mercado - Normalmente as novas tecnologias têm dificuldade de competir com tecnologias dominadas. As tecnologias recém desenvolvidas são, na maior parte dos casos, relativamente ineficientes e caras. Estas características tornam a difusão lenta e difícil. Nestes casos, são usados mecanismos para a criação de espaços protegidos para as novas tecnologias. Algumas possibilidades de proteção são a formação de nichos temporários de mercado, a implementação de regimes favoráveis de tributação e a definição de quotas mínimas de consumo.

- FSI 6) Mobilização de recursos para a inovação - Recursos humanos e financeiros são insumos básicos para impulsionar as atividades dos sistemas de inovação. Para uma 
tecnologia específica, a alocação de recursos suficientes é necessária para viabilizar a produção de conhecimento.

- FSI 7) Criação de legitimidade e contenção da resistência à mudança - Normalmente, a adoção de uma nova tecnologia é acompanhada de um novo regime. Diferentes agentes com interesses contrários ao novo regime terão resistência à mudança. Grupos contra e a favor da tecnologia pressionarão por recursos para pesquisa, diferenciação tributária e demais formas de legitimar o uso da nova tecnologia.

Hekkert et al. (2007) argumentam que as FSI podem influenciar umas às outras. Em função das interações possíveis, podem ser formados motores de transformação do SI. O desempenho de uma determinada FSI pode iniciar o ciclo virtuoso de um processo de mudança, produzindo interações positivas com outras FSI e resultando na transformação do SI. Os autores não propõem qualquer forma pré-definida quanto ao encadeamento das FSI. Não há a discussão de possíveis mecanismos que generalizem o processo de estruturação dos SI. A liberdade na construção dos motores de transformação é uma ferramenta que auxilia a extrair idéias de como a mudança tecnológica está relacionada com a mudança institucional.

\section{Metodologia}

A aplicação empírica do conceito de SI não é tão fácil e direta como aparentemente pode ser concluído. Os pesquisadores devem fazer diversas escolhas quando definem precisamente o SI objeto de análise. O resultado destas escolhas determina qual SI particular é capturado, em termos de suas estruturas e funções. As escolhas influenciam na pesquisa histórica de dados, na interpretação destes e nas conclusões. É preciso comunicar claramente aos leitores o esquema metodológico utilizado na análise. A apresentação do esquema de análise permite discutir os desafios a serem vencidos em cada etapa. (BERGEK et al., 2008)

O ferramental para a análise do Sistema de Produção e Inovação em Açúcar - SPIA será composto pelos seguintes passos metodológicos:

a) definição do SI objeto da análise;

b) identificação dos componentes estruturantes do SPIA;

c) mapeamento dos eventos relevantes para a estruturação do SPIA;

d) identificação das FSI e a formação do motor de transformação;

e) análise do motor de transformação quanto à co-evolução da mudança institucional e tecnológica.

Para Malerba (2004) os SI possuem atividades unificadas por um grupo comum de produtos que atendem uma demanda existente ou potencial. Dessa forma, o primeiro elemento a ser 
identificado no SPIA é o produto sobre o qual os agentes do sistema operam. Na indústria açucareira o produto de interesse comercial é o açúcar, em suas mais deferentes formas (refinado, cristal, standard, etc..). Como subprodutos tem-se o bagaço da cana e o melaço. O álcool de cana, largamente utilizado como bebida, não compõe o SPIA uma vez que seu processo de produção não foi objeto das políticas de modernização do setor. Conforme será visto, a criação dos engenhos centrais não incluiu a cachaça no processo de modernização industrial da época. A cana-de-açúcar é a única matéria-prima da qual o caldo fresco é extraído e destinado a produção do açúcar.

Uma vez que foram definidos o produto e a matérias-prima, cabe evoluir na caracterização do SPIA identificando os agentes que o compõe. Os principais agentes dos SI são as empresas. Elas estão envolvidas na inovação, produção e venda dos produtos que caracterizam o SI. No SPIA as empresas são os engenhos centrais (antiga denominação para as usinas). Além das empresas, o SPIA apresenta um agente criado a partir do processo de modernização: os fornecedores de cana. Esses agentes tinham a função de plantar e fornecer a matéria-prima essencial da indústria. O SPIA pode reunir ainda instituições de pesquisa, organizações financeiras e órgãos de governo como outros agentes componentes, conforme os eventos a serem estudados.

Dada a importância dos agentes para o funcionamento dos SI, seria absolutamente natural que os mesmo fossem identificados nominalmente na caracterização do SPIA. É preciso observar que a proposta metodológica é analisar o SPIA em termos agregados. Se no processo de mapeamento dos eventos (passo 3) algum agente se destacar ele poderá ser identificado. Entretanto, o mapeamento individualizado dos agentes não é uma premissa de análise. O objetivo é estudar a transformação do SPIA e não o desempenho dos agentes individualmente.

Na seqüência metodológica o passo seguinte é mapear eventos relevantes para a estruturação do SPIA. O mapeamento resulta num conjunto de dados históricos, reunindo todos os eventos relevantes associados ao processo de modernização industrial. O mapeamento inclui a definição do período de tempo a ser contemplado na pesquisa histórica. A publicação do decreto 2.687, em 1875, marca o início do processo de modernização que foi conduzido até o início da década de 1890 . O ano de 1892 é o último a registrar a aprovação dos projetos de instalação dos engenhos centrais, sendo escolhido como marco final de análise. O período de 1875 a 1892 impõe o desafio de encontrar fontes bibliográficas adequadas. Para cumprir esta tarefa, a pesquisa histórica utilizou a Base da Legislação Federal brasileira, disponível no sítio eletrônico www.planalto.gov.br/legislacao, além do trabalho de tese de Queda (1972) e da revisão histórica de Eisenberg (1977).

Após o mapeamento dos dados históricos, o próximo passo metodológico é relacionar os eventos com as sete FSI conceitualmente descritas na revisão bibliográfica. A partir do conjunto de FSI identificadas inicia-se a análise de como cada FSI influenciou no processo de transformação do 
SPIA e, ao mesmo tempo, como cada FSI influenciou as outras FSI. Tem-se um motor de transformação do SPIA quando as FSI podem ser encadeadas numa seqüência lógica e temporal. O motor de transformação deve ser capaz de explicar como o desenvolvimento do SI ocorreu ao longo do tempo e qual o papel das FSI neste desenvolvimento. O motor de transformação pode ser igualmente utilizado para transformações positivas ou negativas nos SI.

O motor de transformação será analisado quanto a co-evolução da mudança institucional e tecnológica. O objetivo final é compreender por que a mudança institucional verificada não foi condição suficiente para a esperada modernização da indústria. Assim, espera-se que o artigo contribua para avançar nas questões endereçadas por Castellaci et al. (2005).

Por fim, é preciso esclarecer algumas questões de terminologia. O artigo usará a expressão senhores de engenho para se referir aos proprietários das antigas unidades de produção de açúcar. Os engenhos coloniais eram unidades que integravam a produção agrícola da cana e a obtenção do açúcar, usando métodos rudimentares de extração (força humana, tração animal ou quedas d'água). Os engenhos centrais eram unidades industriais que utilizavam o vapor d'água como força motriz, sendo caracterizados por uma escala de produção significativamente maior do que a dos engenhos coloniais. Os engenhos centrais cultivavam a menor parte da matéria-prima utilizada, necessitando firmar contratos com os fornecedores de cana. Em sua maior parte, os fornecedores de cana eram antigos senhores de engenho, que optaram por permanecer na fase agrícola de produção quando do processo de modernização industrial, conforme detalhado na próxima sessão.

\section{O processo de modernização da indústria do açúcar no final do século XIX}

Eisenberg (1977) relata que no início da década de 1870 um pequeno grupo de senhores de engenho começou a modernizar suas instalações industriais, utilizando recursos próprios. $\mathrm{O}$ pernambucano Francisco do Rêgo Barros de Lacerda começou a reequipar o Engenho São Francisco da Várzea em 1873. O Barão de Muribeca, tio de Rêgo Barros, começou a modernizar o Engenho São João da Várzea em 1875. Foi ele o primeiro senhor de engenho a adquirir caldeiras a vácuo de efeito múltiplo.

Entretanto, ainda segundo Eisenberg (1977), os esforços de modernização com recursos próprios eram esporádicos e não retratavam o comportamento dos senhores de engenho da época. A disponibilidade de terras virgens, a mão-de-obra escrava e a atitude conservadora dos senhores de engenho se combinavam para uma atitude refratária à adoção de inovações tecnológicas. Estes fatores negativos eram reforçados pela instabilidade do mercado de açúcar e pelo fato de que grande parte dos produtores não dispunha de capitais para a modernização dos engenhos. A predisposição à modernização industrial com recursos próprios era a exceção e não a regra. 
As medidas governamentais publicadas entre 1875 e 1890 criam uma série de incentivos para a modernização da agroindústria açucareira. (BRASIL, 1875; BRASIL, 1881; BRASIL, 1889) A política para o setor incentivou a instalação de engenhos centrais, unidades que poderiam moer um volume significativamente maior de cana quando comparadas aos tradicionais engenhos coloniais.

Publicado em 6 de novembro de 1875, o decreto 2.687 é um marco na política de incentivo à modernização da indústria açucareira no Brasil. (BRASIL, 1875) O governo imperial passou a oferecer crédito, com juros de 7\%aa e prazos de pagamento entre 5 e 30 anos, para apoiar as empresas que desejassem estabelecer engenhos centrais de açúcar de cana. $\mathrm{O}$ artigo $2^{\circ}$ do ato normativo especifica que o crédito tinha seria utilizado "mediante o emprego de aparelhos e processo moderno os mais aperfeiçoados". Para estes empreendimentos haveria a disponibilidade de um total de 30.000:000\$ (trinta mil contos de réis), que seriam concedidos através de Bancos de Crédito Real.

Para criar as condições necessárias de produção, o decreto 2.687/1875 determinou que os interessados em construir engenhos centrais deveriam estar formalmente associados aos proprietários agrícolas da região. O governo formalizava a divisão do trabalho agrícola e industrial, requisitando a apresentação dos contratos de fornecimento de cana e estabelecendo o financiamento da safra. Do valor recebido para a construção dos engenhos centrais, 10\% seria destinado a um Fundo Especial, de responsabilidade de cada empresário, para o financiamento dos fornecedores de cana. O financiamento da safra seria feito pelos proprietários dos engenhos centrais, com juros de $8 \%$ aa e seu valor não poderia exceder $2 / 3$ do valor previsto para a safra em plantio.

O mecanismo de financiamento para instalação de engenhos centrais foi regulamentado seis anos depois, através do decreto 8.357/1881. (BRASIL, 1881) Foram definidos os limites de financiamento (500:000\$ - para engenhos de até 100 t/dia de cana ou 1.000t de açúcar por safra; 750:000\$ - para engenhos de até 200 t/dia de cana ou 2.000t de açúcar por safra; 1.000:000\$ - para engenhos acima de 400 t/dia de cana ou 4.000 t de açúcar por safra) e as atividades passíveis de enquadramento. Duas atividades merecem destaque: toda a fase de pré-investimento, compreendendo estudos de viabilidade, desenhos de aparelhos e descrição de processos produtivos e a construção de vias férreas ou outros meios de transporte para o recebimento de matérias-primas dos fornecedores e escoamento da produção. Dentre as obrigações das companhias beneficiadas constava: usar bitola de 1,0 metro e paradas a cada $15 \mathrm{~km}$ nas vias férreas que construíssem; não utilizar escravos na construção ou operação dos engenhos; constituir um fundo de reserva para substituir equipamentos e modernizar as instalações.

O decreto 8.537/1881 ampliou os benefícios para a instalação engenhos centrais, permitindo o livre uso de madeiras, a preferência de compra de terrenos e a isenção de direitos (impostos) de 
importação sobre máquinas, instrumentos, trilhos e quaisquer aparelhos destinados aos engenhos centrais. A concessão de crédito poderia ser feita a empresas nacionais ou estrangeiras, desde que estas estivessem autorizadas a funcionar no império.

Passados oito anos do primeiro regulamento, às vésperas da proclamação da república, o governo imperial publica uma nova regulamentação, o decreto 10.393/1889. (BRASIL, 1889). A normativa traz para o governo a decisão sobre o porte dos engenhos centrais a serem beneficiados com o sistema de crédito. Para tal definição seriam considerados volume de lavouras disponíveis e o método a ser empregado na extração do açúcar da cana. A política de crédito sofre pequena alteração, em favor dos beneficiários. Os juros passam a ser de até $6 \%$ aa e o prazo estendido de 20 para 25 anos.

A análise dos decretos governamentais evidencia que o principal objetivo da política de modernização açucareira era aumentar a escala produtiva, reduzindo os custos de produção. Para abastecer a demanda dos engenhos centrais era preciso produzir e transportar matérias-primas de outras localidades. $\mathrm{O}$ engenho central passa a depender não só de sua área de cultivo, mas também da cana-de-açúcar cultivada por terceiros. Dessa forma, a política de modernização da indústria açucareira resultou na criação de uma nova classe de agentes: os fornecedores de cana-de-açúcar. A produção dos fornecedores de cana seria destinada aos engenhos centrais e mais tarde às usinas de açúcar e álcool. De 1875 em diante os fornecedores de cana estiveram presentes nas políticas de incentivo e regulação da indústria de açúcar e álcool, especialmente no período do Estado Novo e da Ditadura Militar.

Ainda que governo tenha oferecido incentivos financeiros para a instalação dos engenhos centrais, o processo de modernização da indústria açucareira no Brasil teve alcance limitado. No período de 1875 a 1892 foram autorizadas 101 concessões de financiamentos para a construção de engenhos centrais. Destas, 54 foram revogadas por decurso de prazo ou pela simples desistência de seus beneficiários. Apenas 37 empreendimentos tiveram seus planos de obras, projetos e contratos de fornecimentos de cana aprovados. As autorizações de funcionamento chegaram ao número de 8 . A tabela 1 apresenta os dados consolidados em cada ano. 
Tabela 1 - Atos relacionados com a concessão de empréstimos, aprovação de projetos e autorização de funcionamento de engenhos centrais de açúcar e álcool (período de 1875 a 1892)

\begin{tabular}{cccccc}
\hline Ano & Concessões & $\begin{array}{c}\text { Desistências e } \\
\text { revogações }\end{array}$ & $\begin{array}{c}\text { Prorrogaçóes } \\
\text { de prazo }\end{array}$ & $\begin{array}{c}\text { Projetos } \\
\text { aprovados }\end{array}$ & $\begin{array}{c}\text { Autorizações de } \\
\text { funcionamento }\end{array}$ \\
\hline 1875 & 0 & 0 & 0 & 0 & 0 \\
1876 & 18 & 0 & 3 & 0 & 3 \\
1877 & 2 & 2 & 11 & 0 & 0 \\
1878 & 2 & 0 & 0 & 0 & 0 \\
1879 & 3 & 0 & 0 & 0 & 0 \\
1880 & 7 & 0 & 4 & 0 & 0 \\
1881 & 9 & 16 & 2 & 0 & 1 \\
1882 & 12 & 1 & 6 & 0 & 0 \\
1883 & 4 & 3 & 3 & 10 & 0 \\
1884 & 6 & 1 & 5 & 0 & 2 \\
1885 & 4 & 9 & 2 & 6 & 1 \\
1886 & 1 & 1 & 0 & 0 & 0 \\
1887 & 0 & 4 & 1 & 1 & 0 \\
1888 & 3 & 3 & 1 & 0 & 0 \\
1889 & 17 & 9 & 1 & 8 & 0 \\
1890 & 13 & 0 & 6 & 3 & 1 \\
1891 & 0 & 0 & 2 & 5 & 0 \\
1892 & 0 & 5 & 0 & 4 & $\mathbf{8}$ \\
TOTAL & $\mathbf{1 0 1}$ & $\mathbf{5 4}$ & $\mathbf{4 7}$ & $\mathbf{3 7}$ & \\
\hline F & 1 & & & & \\
\hline
\end{tabular}

Fonte: Base da Legislação Federal.

Em 1891 o Ministério da Agricultura avaliou que o resultado da modernização da indústria de açúcar no Brasil era insuficiente. Apesar da alta demanda pelos recursos a maior parte dos interessados era formada por pessoas estranhas ao setor que, segundo o Ministério, tinham por objetivo negociar as concessões obtidas. O Ministério da Agricultura informa a existência de 13 engenhos centrais em operação, número diferente dos 8 verificados com a análise dos decretos do período (vide tabela anterior) (BRASIL, 1891).

Mesmo considerando a existência de 13 engenhos centrais, esse número é inexpressivo quando comparado ao número total de engenhos que operavam no sistema antigo de produção. Em 1877 existiam cerca de 2.600 engenhos nos Estados de Pernambuco, Alagoas, Sergipe e Bahia. (BRASIL, 1938) Considerando que não estão presentes neste levantamento os Estados de Minas, Rio de Janeiro e São Paulo, é bastante razoável concluir que a modernização da indústria açucareira não ocorreu na extensão planejada pelo governo.

Em síntese, a política de modernização da indústria açucareira não conseguiu atingir o objetivo de aumentar a competitividade do açúcar através do aumento da produtividade. Entretanto, apesar de poucos, a instalação dos engenhos centrais introduziu a criação de uma nova classe de atores no sistema de produção e inovação: os fornecedores de cana. O decreto 2.687/1875 marca o início da relação entre dois atores que, ao longo do tempo, se colocariam em campos opostos.

Queda (1972) observa que a característica fundamental na constituição dos engenhos centrais foi a separação entre a fase agrícola e industrial. A construção dos engenhos centrais exigia capitais em volume que os senhores de engenho não podiam mobilizar. Na divisão de trabalho a 
atividade industrial foi formada, em sua maior parte, por grupos europeus. A maioria dos senhores de engenho, sem condições de arcar com os requisitos de empréstimo se mantiveram na fase agrícola, fornecendo cana-de-açúcar aos engenhos centrais.

Queda (1972) analisou os debates do Congresso Agrícola do Norte, realizado em 1878 em Recife, tendo como patrocinadora a Sociedade Auxiliadora de Agricultura de Pernambuco. A análise confirma que a iniciativa pela separação das atividades agrícolas e industriais foi incentivada pelos próprios senhores de engenho, que optaram por manter seus negócios no cultivo da cana-de-açúcar para manter o domínio territorial em suas regiões de influência política.

Em seu pronunciamento no Congresso, o Sr. Vicente Cisneiras defendia que a separação das atividades era fundamental para a melhorar a situação do negócio açucareiro do Nordeste. Outro palestrante, o Sr. Vitor de Sá Barreto também defendia a tese da separação, pronunciando: “(...) dividi o trabalho; fabricai o açúcar, ou plantai a cana.” (IAA, 1949) A falta de capital e o direcionamento político estimularam a decisão dos antigos senhores de engenho de manterem sobre seu controle a atividade agrícola de produção de cana. Na revisão bibliográfica não há qualquer referência de ação dos senhores de engenho contra o movimento que os tornou fornecedores de cana.

A divisão de trabalho criada com a implementação dos engenhos centrais trouxe uma série de atritos. Para a separação das fases agrícola e industrial foi preciso criar mecanismos de mediação, o que era dificultado em função das características do mercado de açúcar. Os principais problemas estavam relacionados a: volatilidade do preço do açúcar, com seus impactos no preço da matéria-prima; o elevado custo do transporte da cana; o fato de que, quando madura a cana deve ser cortada para não perder o teor de sacarose; quando cortada deve ser entregue imediatamente para o processamento.

Queda (1972) avalia que a irregularidade no fornecimento e os atritos entre fornecedores e industriais impediram que os objetivos da política de implementar os engenhos centrais fossem alcançados.

O processo de modernização da indústria do açúcar iniciado em 1875 trouxe a separação dos agentes responsáveis pelas fases agrícola e industrial. Essa divisão de funções está presente ainda nos dias hoje. A relação entre fornecedores e industriais foi objeto de regulação do Estado até o final do século XX, produzindo efeitos significativos na estruturação e crescimento da indústria sucroalcooleira.

\section{O motor de transformação associado à modernização do SPIA}


O processo de modernização da agroindústria do açúcar e do álcool tem início na década de 1870. Entretanto, os pioneiros da modernização industrial do açúcar eram exceção. Os maiores entraves ao processo de modernização estavam relacionados com a instabilidade do mercado de açúcar e a indisponibilidade de recursos financeiros dos senhores de engenho. O governo imperial respondeu ao início do processo de modernização com a publicação do decreto 2.687/1875. O decreto 2.687/1875 é um marco no processo de modernização, representando a decisão política do Estado em melhorar a competitividade do açúcar brasileiro no mercado externo. O objetivo do governo foi proporcionar condições financeiras para os investimentos pudessem ser realizados. O direcionamento de recursos foi firme e duradouro, caracterizando a respectiva função (FSI 6) no SPIA.

A disponibilidade de recursos para a modernização industrial tinha por objetivo a criação de novas unidades produtivas. Ou seja, os agentes do sistema desempenhariam a função de realizar atividades empreendedoras (FSI 1). Entretanto, os empreendimento não acompanharam a disponibilidade de recursos. No período de 1875 a 1892 foram autorizadas 101 concessões de financiamentos para a construção de engenhos centrais. Destas, 54 foram revogadas por decurso de prazo ou pela simples desistência de seus beneficiários. Apenas 37 empreendimentos tiveram seus planos de obras, projetos e contratos de fornecimentos de cana aprovados. As autorizações de funcionamento chegaram ao número de 8.

Em 1891 o Ministério da Agricultura avaliou que o resultado da modernização da indústria de açúcar no Brasil era insuficiente (MACOP, 1891). Apesar da alta demanda pelos recursos a maior parte dos interessados era formada por pessoas estranhas ao setor que, segundo o Ministério, tinham por objetivo negociar as concessões obtidas. O Ministério da Agricultura registrou a existência de 13 engenhos centrais em operação, número diferente dos 8 verificados com a análise dos decretos do período.Mesmo considerando a existência de 13 engenhos centrais, este número é inexpressivo quando comparado ao número total de engenhos existentes no País. Em síntese, o processo de modernização da indústria açucareira no Brasil teve alcance limitado.

A mobilização de recursos tinha por objetivo gerar estímulos aos empreendedores, de forma que estes se interessassem pela instalação de engenhos centrais. A política de modernização seria concretizada com a instalação e operação de novas unidades industriais, com processos de produção mais modernos, o que não ocorreu. O número de projetos autorizados a funcionar representou cerca de $8 \%$ do total de concessões efetuadas. A FSI de atividades empreendedoras falha e o motor de transformação do SI não se efetiva.

A baixa mobilização para atividades empreendedoras é a principal razão do não funcionamento do motor de transformação. Entretanto, o desenvolvimento do motor também esbarrou na resistência ao novo regime de trabalho. A função de criação de legitimidade e 
contenção da resistência à mudança (FSI 7) era necessária ao motor de transformação, mas não se desenvolveu.

A característica fundamental na constituição dos engenhos centrais foi a separação, artificialmente determinada, entre a fase agrícola e a fase industrial. A instalação dos engenhos centrais implicou numa escolha forçada. Os empresários do setor que não se tornassem proprietários de engenhos centrais teriam a opção de permanecerem na fase agrícola de produção, tornando-se fornecedores de cana, ou sair da atividade. Enraizados na tradicional cultura do poder fundiário e com pouca disponibilidade de capital, grande parte dos senhores de engenho permaneceu na fase agrícola da produção. A análise das escolhas realizadas pelos senhores de engenho confirma que a opção pela manutenção da atividade agrícola partiu dos próprios senhores de engenho.

A separação das atividades agrícola e industrial iniciou uma série de conflitos entre fornecedores de cana e industriais, que envolviam os valores a serem pagos pela cana, o volume de produção, a garantia de compra da cana-de-açúcar, entre outros aspectos. As disputas de poder eram especialmente presentes no norte fluminense e na região nordeste, onde a cana-de-açúcar era uma cultura secular. O poder político dos antigos senhores de engenhos passou a ser exercido pelos novos fornecedores de cana. Ainda que não detivessem o poder econômico, agora com os engenhos centrais, os fornecedores de cana formavam uma classe influente no plano político.

A modernização da agroindústria do açúcar e do álcool não ocorreu na extensão desejada. Não houve a transformação do SI no sentido pretendido pela política governamental. A realização de atividades empreendedora era uma condição necessária para a transformação dos SI. Entretanto, a criação de uma nova categoria de atores, os fornecedores de cana, foi um subproduto concreto e duradouro. Trata-se de um resultado colateral que produziu efeitos na agroindústria do açúcar e do álcool por quase um século. A figura 1 resume as relações entre as FSI para o processo de modernização da indústria açucareira do Brasil no final do século XIX. 
Figura 1 - Representação esquemática das falhas no motor de transformação associado à modernização da indústria açucareira no final do século XIX no Brasil

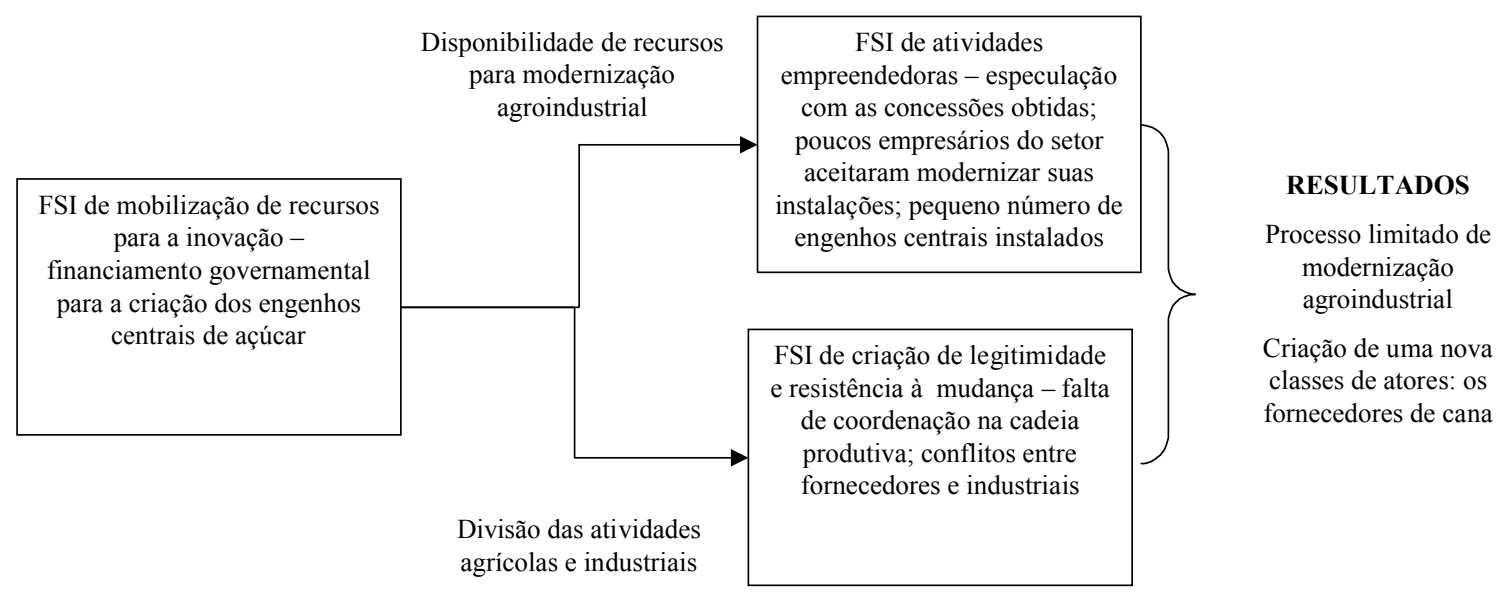

Fonte: Autoria própria (2009).

\section{Conclusão}

No motor de transformação associado à modernização da indústria açucareira observa-se uma aparente interação entre mudança tecnológica e mudança institucional. A introdução dos engenhos centrais seria uma verdadeira revolução tecnológica, possibilitando o aumento das escalas produtivas e a redução dos custos. A mudança dos engenhos coloniais para unidades industriais, de alta escala de produção, poderia ser considerada como um processo de transformação técnica.

Das 101 concessões de empréstimos para a instalação de engenhos centrais apenas 8 autorizações de funcionamento foram emitidas. A transformação do regime tecnológico não ocorreu com a velocidade e abrangência esperada pelo governo quando da publicação do decreto 2.687/1875. Entretanto, a mudança do regime tecnológico foi acompanhada por uma significativa mudança institucional. O engenho colonial, de método arcaico, foi substituído por dois novos agentes: o engenho central e os fornecedores de cana-de-açúcar. Então, se houve mudança institucional, qual a razão para que o novo regime tecnológico não fosse plenamente estabelecido?

No Brasil do final do século XIX, a relação da cana com o açúcar é unívoca nos dois sentidos. Essa característica torna a interação das fases agrícola e industrial um requisito para o sucesso da atividade açucareira. Dentre outros aspectos, a interação deveria envolver: o fornecimento de cana em quantidade e prazos previamente acordado, as pesquisas para aumentar o teor de sacarose na cana, o controle sanitário para maximizar o crescimento da planta e o uso de sistemas de irrigação.

Ao otimizar o rendimento industrial os engenhos centrais criam valor para si, valor que foi plenamente apropriável. Os fornecedores de cana criam valor para os engenhos centrais quando 
entregam matérias-primas de melhor qualidade e de maior teor de sacarose o que não significa, necessariamente, a retenção de valor para si. Como a matéria-prima era remunerada por peso bruto, que diferença teria para o fornecedor entregar canas com $8 \%$ de sacarose ou com $18 \%$ ? Essa foi a situação vivida na região Nordeste e no norte fluminense quando do processo de modernização do setor açucareiro. A mudança institucional ocorreu por uma imposição governamental, estabelecida em decreto. Os agentes não se moldaram de forma a criar valor mútuo; a relação entre os fornecedores e os engenhos centrais era de conflito e não de cooperação. A ausência de uma relação que permitisse a mútua criação de valor impediu o estabelecimento de uma mudança institucional sustentável, resultando na ineficácia da mudança tecnológica.

É preciso esclarecer que em certa medida os antigos engenhos foram substituídos por unidades modernas de produção. Entretanto, até 1892, isso não pode ser interpretado como uma verdadeira mudança no regime tecnológico. Para que a mudança fosse plena, seria preciso um processo muito mais amplo de substituição dos antigos engenhos pelas novas unidades. A mudança institucional não co-evoluiu com a mudança tecnológica.

Apesar de serem dependentes de seus fornecedores, os proprietários de engenhos centrais não souberam ou não conseguiram estabelecer um sistema que incentivasse melhorias no rendimento do cultivo da cana. O baixo rendimento na produção e qualidade da matéria-prima limitava a apropriação de valor. Colaborou nesse processo os fatores culturais associados ao cultivo da cana no Brasil, onde os senhores de engenho tinham fortes relações com o poder político. Os fornecedores de cana do Nordeste do Brasil e do norte fluminense eram mais do que produtores de matérias-primas, eram herdeiros do poder político transmitido por aqueles que um dia foram senhores de engenho.

Da discussão anterior pode-se inferir que a mudança institucional pode ser uma condição necessária para a mudança tecnológica, mas não é suficiente. Sem a devida apropriação de valor pelos agentes envolvidos o regime tecnológico não se desenvolve. Os fornecedores de cana e os engenhos centrais materializam a mudança institucional, mas não conseguiram estabelecer uma forma eficiente de repartir o valor gerado.

\footnotetext{
Abstract

This paper aims to discuss the co-evolution between technological and institutional changes. The paper also advances the concept of innovation systems in literature. The study uses the structure of motors of change as an analysis tool. The methodology defines the Sugar Systems of Innovation and Production - SPIA. Referring to SPIA, the modernization of sugar industry serves as the object of analysis. The paper conclusion is that institutional change was a necessary condition to technological change, but it was not enough. The government influence resulted in a new participant - the cane suppliers - who started interacting with sugar plants. However, the cane
} 
suppliers and the sugar plants did not divide the value generated. Sugar plants retained almost all the value. Consequently, the institutional and technological change did not co-evolved in SPIA The institutional change that occurred did not lead to a technological change.

Key-words: innovation systems, motors of change, institutional change, technological change, coevolution.

\section{Referências}

BALZAT, M.; HANUSCH, H.. Recent trends in the research on national innovation systems. Journal of Evolutionary Economics. v. 14, p. 197-210. 2004.

cross ref

BERGEK, A. et al. Analyzing the functional dynamics of technological innovation system: a scheme of analysis. Reserch Policy, v. 37, p. 407-429. 2008.

BRASIL. Decreto no 2.687, de novembro de 1875. Autoriza o Governo para conceder, sob certas cláusulas, ao Banco de Credito Real que se fundar segundo o plano da Lei ${ }^{\circ} 1.237$ de 24 de Setembro de 1864, garantia de juros e amortização de suas letras hipotecárias, e bem assim para garantir juros de $7 \%$ às companhias que se prepuserem a estabelecer engenhos centrais para fabricar açúcar de cana. Base da Legislação Federal. Disponível em: http://www.planalto.gov.br.

BRASIL. Decreto no 8.357, de dezembro de 1881. Aprova o regulamento para as concessões de engenhos centrais, com garantia de juros ou fiança do Estado. Base da Legislação Federal. Disponível em: http://www.planalto.gov.br.

BRASIL. Decreto no 10.393, de outubro de 1889. Dá regulamento para execução do decreto legislativo no 2.687 de 6 de novembro de 1875 na parte referente á fundação de engenhos centrais para fabrico de açúcar e de álcool de cana. Base da Legislação Federal. Disponível em: http://www.planalto.gov.br.

BRASIL. Ministério da Agricultura, Comércio e Obras Públicas. Relatório de atividades - junho de1891. Rio de Janeiro: Imprensa Nacional, 1891.

BRASIL. Departamento Nacional de Propaganda. O açúcar sob o governo Getúlio Vargas. Rio de Janeiro: Editora Amorim e Cia, 1938.

BUnGE, M. A.. Treatise on Basic Philosophy. v. 4, New York: Hardcover, 1979. 336 p.

CARLSSON, B.. Internationalization of innovation systems: a survey of the literature. Research Policy, v. 35, p. 56-67. 2006.

cross ${ }^{\text {ref }}$

CASTELLACCI, F. et al. Advances and challenges in innovation studies. Journal of Evolutionary Economics, v. 39 , n. 1, p. 91-121. 2005.

CESNIK, R. MIOCQUE. J.. Melhoramento da cana-de-açúcar. Brasília: Editora da Embrapa, 2004. 307 p.

COOKE, P.; URANGA, M. G.; ETXERBARRIA, G.. Regional innovation systems: institutional and organizational dimensions. Research Policy, v. 26, p. 475-491. 1997.

cross ${ }^{\text {ef }}$

DE CARLI, G.. O açúcar na formação econômica do Brasil. Anuário Açucareiro, Rio de Janeiro: Editora do IAA,. 1936.

EDQUIST, C.. Introduction. In: Edquist, C. (Ed.), Systems Of Innovation: Technologies, Organizations and Institutions. Londres: Pinter Publishers, 1997. 320 p.

Systems of innovation: perspectives and challenges. In: Fagerberg, Mowery e Nelson (Ed.), The Oxford Handbook of Innovation, London: Oxford University Press. 2005. 656 p.

EISENBERG, P. L.. Modernização sem mudança: a indústria açucareira em Pernambuco 1840-1910. Rio de Janeiro: Editora Paz e Terra, 1977. 
FREEMAN, C.. Technology Policy and Economic Performance: Lessons From Japan. Londres: Continuum International Publishing, 1987. 168 p.

FURMAN, J. L.; PORTER, M. E.; STERN, S.. The determinants of national innovative capacity. Research Policy, v. 31, n. 6, p. 899-933. 2002.

cross ${ }^{\text {ref }}$

FURTADO, C.. Formação econômica do Brasil. São Paulo:Companhia Editora Nacional, 32º ed, 1959. 256 p.

GEELS, F. W.. From sectoral systems of innovation to socio-technical systems: insights about dynamics and change from sociology and institutional theory. Research Policy, v. 33, p. 897-920. 2004.

cross ${ }^{\text {ref }}$

Processes and patterns in transitions and system innovations: refining the co-evolutionary multi-level perspective. Technological Forecasting and Social Change, n. 72, p. 681-696. 2005.

cross ${ }^{\text {ref }}$

HEKKERT, M. P. et al. Functions of innovation systems: a new approach for analysing technological change. Technological Forecasting and Social Change, v. 74, p. 413-432. 2007.

INSTITUTO DO AÇÚCAR E DO ÁLCOOL - IAA. Congressos açucareiros no Brasil. Rio de Janeiro: Editora do IAA, 1949.

cross ${ }^{\text {ref }}$

JACOBSSON, S.; JOHNSON, A.. The diffusion of renewable energy technology: an analytical framework and key issues for research. Research Policy, v. 28, p. 625-640. 2000.

LEONTIEF, W. (1941) apud CARLSSON, .B. et al. Op. Cit., p. 235. 2002.

LUNDVAL, B. A.. Innovation as an interaction to the national system of innovation. In: Dosi et al (Ed.), Technical Change and Economic Theory, London: Frances Pinter, 1988. 656 p.

cross $^{\text {ref }}$

. National Systems of Innovation: Towards a Theory of Innovation and Interactive Learning. Londres: London Priter, Londres, 1992. 342 p.

LUNDVAL, B. A. et al. National systems of production, innovation and competence bulding. Research Policy, v. 31, p. 213-231. 2002.

MALERBA, F.. Sectoral systems of innovation and production. Research Policy, v. 31, p. 247-264. 2002.

cross ${ }^{\text {ref }}$

. Sectoral systems of innovation: basic concepts. In: MALERBA, F. (Ed.), Sectoral Systems of Innovation, Cambridge: Cambridge University Press, p. 9-41. 2004. 536 p.

; ORSENIGO, L.. Schumpeterian patterns of Innovation are technology-specific. Research Policy, v. 25, p. 451-478. 1996.

cross'

NELSON, R. R.. National Systems of Innovation: A Comparative Analysis. 1. ed. Oxford: Oxford University Press, 1993. $560 \mathrm{p}$.

QUEDA, A.. A intervenção do Estado e a agroindústria açucareira paulista. Dissertação (Doutorado) - Escola Superior de Agricultura Aloísio de Queiroz, Universidade de São Paulo, Piracicaba. 1972.

Dados completos dos autores:

Nome completo: Fabrício Brollo Dunham

Filiação institucional: Financiadora de Estudos e Projetos - FINEP

Departamento: Departamento de Estudos, Planos e Programas 
Função ou cargo ocupado: Secretário Técnico

Endereço completo para correspondência (bairro, cidade, estado, país e CEP): Praia do Flamengo, $200 / 13^{\circ}$ andar - Rio de Janeiro - RJ - Brasil - CEP 22.210-030

Telefones para contato: 21 2555-0221

e-mail: fbrollo@finep.gov.br

Nome completo: José Vitor Bomtempo

Filiação institucional: Universidade Federal do Rio de Janeiro - UFRJ

Departamento: Departamento de Engenharia Química

Função ou cargo ocupado: Pesquisador

Endereço completo para correspondência (bairro, cidade, estado, país e CEP): Centro de Tecnologia

- bloco E - sala 209 - Fundão - Rio de Janeiro - RJ - Brasil - CEP 21.949-900

Telefones para contato: 21 2266-2464

e-mail: vitor@eq.ufrj.br

Recebido para publicação em: 16/01/2009

Aceito para publicação em: 12/03/2009 